\title{
The Prognostic Significance of Complete Response Rates in Patients with Extensive Stage Small Cell Lung Cancer
}

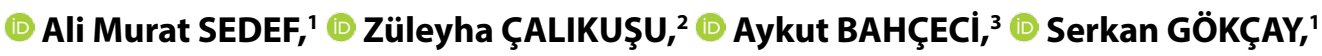 \\ (D) Ahmet Taner SÜMBÜL ${ }^{4}$ \\ 'Department of Medical Oncology, Şanlıurfa Mehmet Akif İnan Education and Research Hospital, Şanlıurfa-Turkey \\ 2Department of Medical Oncology, Acıbadem Mehmet Ali Aydınlar University, Adana-Turkey \\ ${ }^{3}$ Department of Medical Oncology, Ersin Arslan Training and Research Hospital, Gaziantep-Turkey \\ ${ }^{4}$ Department of Medical Oncology, Başkent University, Faculty of Medicine, Adana-Turkey
}

\begin{abstract}
OBJECTIVE
Small cell lung cancer (SCLC) is the most aggressive type of lung cancer. Platinum-etoposide chemotherapy combination is used as first line treatment. The aim of this trial is evaluate the effect of complete response rates and clinical features in patients with extensive stage (ES) SCLC.

\section{METHODS}

In this retrospective study, a total of 117 patients from four different oncology centers in Turkey between 2011 and 2017 were divided into 2 groups, namely, patients with complete response (group 1) and those with no complete response (group 2) after platin-etoposide combination therapy.

\section{RESULTS}

The median age of the patients was 61 (range 38-81) years. The median follow-up time was 12 months and 95 (81\%) patients died. Progression-free survival (PFS) and overall survival (OS) were estimated, respectively, as 8 and 13 months. Overall survival of group 1 patients was statistically significantly better than the group 2 ( 16 versus 10 months respectively and $p=0.00$ ). The overall survival of patients who had late recurrent disease ( $>6 \mathrm{mo}$.) was statistically significantly better than the early ones $(<6 \mathrm{mo})(19$ versus 14 months respectively and $\mathrm{p}=0,008)$.

\section{CONCLUSION}

Complete response and recurrent free time were the prognostic factors for ES SCLC patients in our study

Keywords: Complete response; prognosis; small cell lung cancer.

Copyright $\odot$ 2019, Turkish Society for Radiation Oncology
\end{abstract}

\section{Introduction}

Small cell lung cancer (SCLC) is a neuroendocrine tumor that represents approximately $15 \%$ of all lung cancers, and the estimated number of cases of SCLC is approximately 29,000 in 2016.[1,2] SCLC is distinguished from other tumors by rapid growth with early development of metastases. Most of patients present at the extensive stage and cannot be treated with curative treatment modalities, such as chemoradiotherapy. Patients have short symptom duration. Prognostic factors include European Cooperative Oncology Group (ECOG) performance status, gender, stage, number and location of metastases, SIADH, and treatment response. The backbone of actual SCLC treatment is combined chemotherapy and radiotherapy and less frequently and carefully in selected cases, surgical procedures. Despite enormous efforts for the treatment of

\author{
Şanlıurfa Mehmet Akif İnan Eğitim ve Araştırma Hastanesi, \\ Tıbbi Onkoloji Anabilim Dalı, \\ Şanlıurfa-Turkey \\ E-mail: alimuratsedef@gmail.com
}


SCLC, There is no targeted treatment strategies or investigational immunotherapeutic agents resulted in significant improvement of survival parameters for these patients. Platinum analogues, in particular cisplatin, have been the mainstay of first-line treatment over 40 years, and combination therapies have been found to be superior to single agent [4] treatments. The most commonly used treatment combination for the first-line treatment is the platinum-etoposide regimen. The complete response obtained by treatment has prognostic significance in patients with extensive stage (ES)-SCLC.

In this study, we aimed to evaluate the prognostic role of complete response rate and clinical outcomes in ES-SCLC.

\section{Materials and Methods}

We designed this study to evaluate the prognostic role of treatment responses on the survival parameters in ES-SCLC treated with cisplatin-based combination regimen. This study was a hospital-based retrospective observational case series study. Among 1500 newly diagnosed patients with lung cancer at the Sanliurfa Mehmet Akif Inan Education and Research Hospital, Acıbadem Mehmet Ali Aydinlar University, Ersin Arslan Training and Research Hospital, and Baskent University Departments of Medical Oncology between 2011 and 2017, there were 117 patients with ES-SCLC. Demographic data were collected together with the outcome of chemotherapy.

\section{Statistical Analysis}

All results were presented as the rate of categorical values or mean and median for continuous variables. Clinical and statistical significant correlation between continuous variables was calculated by Spearman's rank correlation test, and Spearman's correlation coefficient and $\mathrm{p}$ value ( 2 tailed) were noted. Overall Survival (OS) was defined by the time from the date of death and last control minus the first day of the chemotherapy. Survival curves were estimated according to the Kaplan-Meier method, and log-rank tests were used for univariate statistical comparisons. Adjusted hazard ratio and 95\% confidence interval were used for estimation. All statistical data were analyzed using the SPSS version 17.0, and a $p$ value $<0.05$ was considered statistically significant.

\section{Results}

\section{Study Patients}

Patient characteristics are shown in Table 1 . The median age of the patients was 61 (range, 38-81) years, and $105(89.7 \%)$ patients were male. All of the patients $(n=117)$ had stage 4 of the disease, and $86(73.5 \%)$ patients had oligometastatic disease. Further, 21 (17.9 $\%)$ patients had cranial metastases, and 43 (36.8\%) patients had liver metastases. All patients were treated with the platinum-etoposide combination regimen, and 111 patients $(94.9 \%)$ received cisplatin in combination. Patients were divided into two groups according to treatment response: Group $1(n=65)$ consisted of patients with complete response at the end of treatment, and Group $2(n=52)$ consisted of patients with incomplete response at the end of treatment.

\section{Treatment and Outcomes}

The median follow-up time was 12 months, and 95 (81\%) patients were deceased. Progression-free survival and OS were estimated as 8 and 13 months, respectively (Figs. 1 and 2). Further, 65 (55.6\%) patients (Group 1) had complete response at the end of first-line

Table 1 Patient and tumor characteristics

\begin{tabular}{lc} 
Characteristics & $\mathbf{n}(\%)$ \\
\hline $\begin{array}{l}\text { Median age } \\
\text { Gender }\end{array} \quad 61(39-83)$ years old \\
$\quad$ Men & $105(89.7)$ \\
$\quad$ Women & $12(10.3)$ \\
Oligometastatic disease & \\
$\quad$ Yes & $86(73.5)$ \\
$\quad$ No & $31(26.5)$ \\
Cranium Metastases & \\
$\quad$ Yes & $21(17.9)$ \\
$\quad$ No & $96(82.1)$ \\
Liver Metastases & \\
Yes & $43(36.8)$ \\
No & $74(63.2)$
\end{tabular}

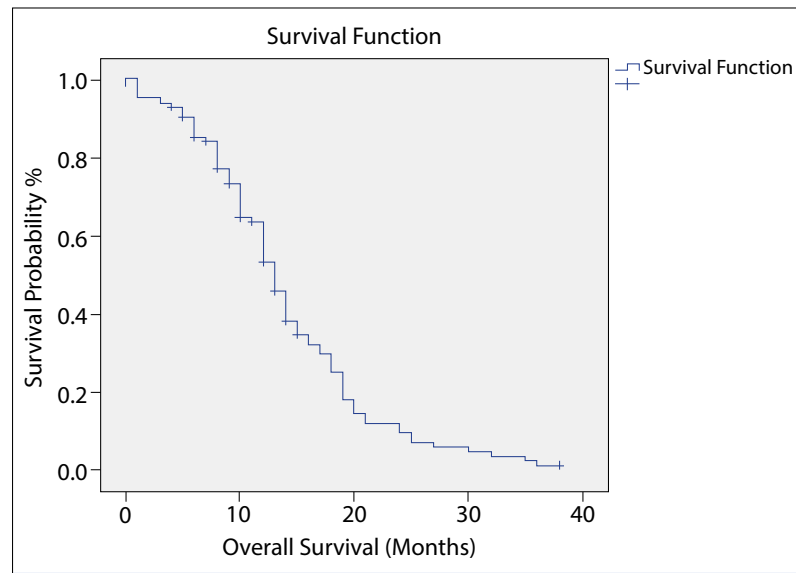

Fig. 1. Kaplan-Meier estimates of overall survival (OS). 


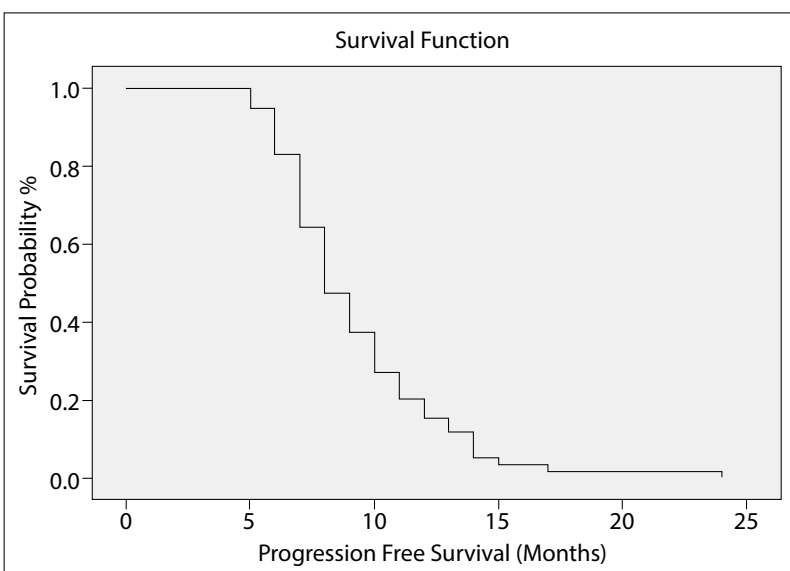

Fig. 2. Kaplan-Meier estimates of progression-free survival.

\section{Table 2 Treatment and outcomes}

\begin{tabular}{lc} 
Characteristics & $\mathbf{n}$ \\
\hline $\begin{array}{l}\text { Chemotherapy r egimen } \\
\quad \text { Cisplatin-Etoposide }\end{array}$ & \\
$\quad$ Carboplatin-Etoposide & $111(94.9)$ \\
Complete Response to first-line treatment & $6(5.1)$ \\
$\quad$ Yes & \\
$\quad$ No & $65(55.6)$ \\
Complete response time & $52(44.4)$ \\
$\quad$ Interim analysis & \\
$\quad$ End of treatment & $18(15.4)$ \\
Disease recurrence & $47(40.2)$ \\
$\quad$ Yes & \\
$\quad$ No & $59(50.4)$ \\
Disease recurrence time & $6(5.1)$ \\
$\quad<6$ Months & \\
$\quad>6$ Months & $37(31.6)$ \\
Final status & $22(18.8)$ \\
$\quad$ Died & \\
Alive & $95(81.2)$ \\
& $22(18.8)$
\end{tabular}

platinum-etoposide combination treatment. Additionally, 18 (15.4\%) of the Group 1 patients had complete response in the interim analysis and 47 (40.2) of the Group 1 patients had complete response at the end of the treatment. Moreover, 59 (90.7\%) patients of Group 1 had recurrent disease, and 37 (31.6) patients showed recurrence in less than 6 months. The treatment of the patients and their results are shown in Table 2.

OS of Group 1 patients was significantly better than that of Group 2 patients ( 16 vs. 10 months, $p=0.00$ ) (Fig. 3). OS of patients who had recurrent disease after 6 months from the response time was significantly better than that of patients who had recurrent disease in

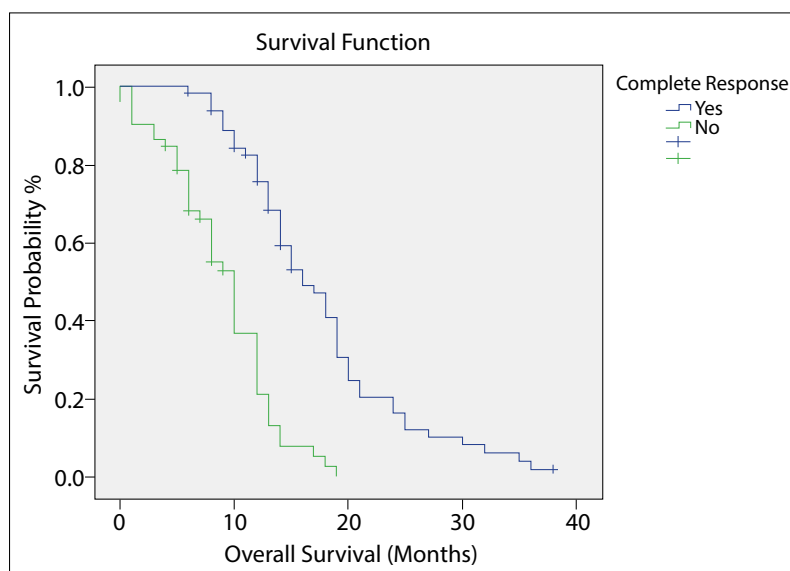

Fig. 3. Kaplan-Meier estimates of OS for Group 1 (responders) and Group 2 (non-responders).

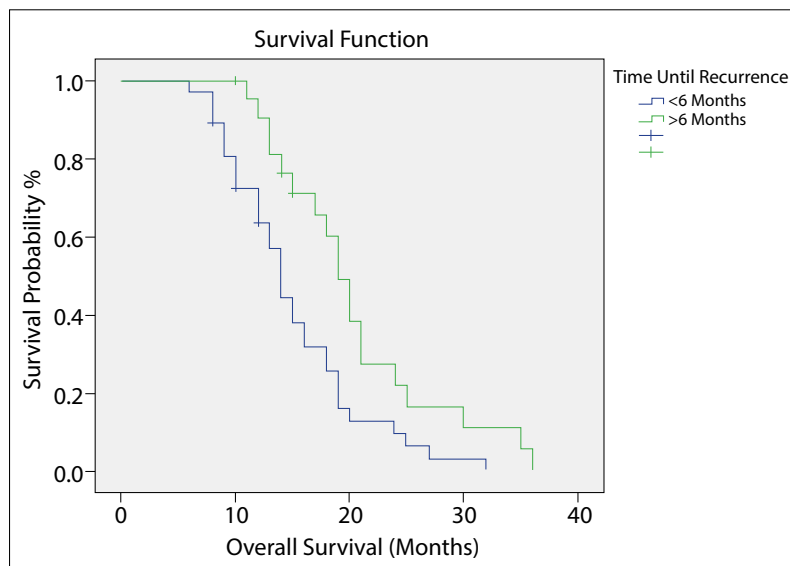

Fig. 4. Kaplan-Meier estimates of OS according to recurrence time.

less than 6 months ( 19 vs. 14 months, $\mathrm{p}=0.008$ ) (Fig. 4). OS was better for patients with oligometastatic disease than for other patients ( 14 vs. $9, \mathrm{p}=0.002$ ), and the OS of patients with liver metastasis was worse than that of other patients ( 10 vs. 14 months, $\mathrm{p}=0.000$ ). In addition, presence of brain metastasis and time to complete response (interim or end of treatment) were not effective on median survival.

\section{Discussion}

In this study we reviewed the prognostic significance of complete response rates and other clinical factors in patients with ES-SCLC. In this study, the complete response rates after treatment and the recurrence-free period were found effective on OS. The median OS time of the patients who had complete response after 
treatment was significantly better than non-complete responders, and patients with a disease-free period of more than 6 months had better survival.

SCLC is a disseminated disease in most patients at presentation, and it is very responsive to chemotherapy. The most important prognostic factor in patients with SCLC is the extent of disease (stage) at presentation. For patients with ES disease, the median survival is $8-13$ months, and the 5 -year survival rate is $1 \%-2 \%$. For patients who respond well to first-line systemic therapy, radiation therapy (prophylactic cranial and thoracic therapy) may provide additional benefits. Therefore, complete response to treatment is important for prognosis. The median survival of patients with relapsed SCLC ranges from 2 to 6 months. [3] Generally, second-line chemotherapy is less effective than initial treatment for patients who have recurrent disease. The length of response to initial treatment influences the likelihood of response to subsequent treatment. Therefore, time to recurrence has prognostic significance. Especially in the patients with late relapses, at least 6 months after treatment, time to recurrence has better prognosis than in patients with early relapses.

In accordance with the information on SCLC, the prognosis of patients who had complete response to treatment was better than that of other patients (noncomplete responders) in our study. However, no statistically significant relationship was found between response time (interim or end of treatment) and OS. The patients who experienced relapse within 3 months of the last day of initial treatment constitute the treatment-resistant group. But in our study, OS rates were better in patients whose recurrence-free period was less than 6 months. Prognostic importance of relapse-free survival was shown in our study, and it was compatible with literature. Additionally, in our study, patients with liver metastases had worse prognosis, and these findings are consistent with previous reports of patients with SCLC with and without hepatic metastasis.[4-6]

\section{Conclusion}

In conclusion, complete response rates and long relapse-free period are associated with a good prognosis in patients with ES-SCLC.

Peer-review: Externally peer-reviewed.

Conflict of Interest: No conflict of interest.

Financial Support: No support.

Authorship contributions: Concept - A.M.S.; Design A.M.S., A.T.S.; Supervision - A.T.S.; Materials - S.G., A.B., Z.Ç., A.M.S.; Data collection \&/or processing - A.M.S., S.G.; Analysis and/or interpretation - Z.Ç.; Literature search A.M.S., A.B.; Writing - A.M.S., A.T.S.; Critical review - A.T.S.

\section{References}

1. Govindan R, Page N, Morgensztern D, Read W, Tierney R, Vlahiotis A, et al. Changing epidemiology of small-cell lung cancer in the United States over the last 30 years: analysis of the surveillance, epidemiologic, and end results database. J Clin Oncol 2006;24(28):4539-44.

2. Miller KD, Siegel RL, Lin CC, Mariotto AB, Kramer $\mathrm{JL}$, Rowland JH, et al. Cancer treatment and survivorship statistics, CA Cancer J Clin 2016;66(4):271-89.

3. Albain KS, Crowley JJ, Livingston RB. Long-term survival and toxicity in small cell lung cancer. Expanded Southwest Oncology Group experience. Chest 1991;99(6):1425-32.

4. Wang X, Teng F, Kong L, Yu J. Pretreatment neutrophil-to-lymphocyte ratio as a survival predictor for small-cell lung cancer. OncoTargets Therapy 2016;9:5761-70.

5. Shao N, Cai Q. High pretreatment neutrophil-lymphocyte ratio predicts recurrence and poor prognosis for combined small cell lung cancer. Clin Transl Oncol 2015;17(10):772-8.

6. He Y, Wang Y, Boyle T, Ren S, Chan D, Rivard C, et al. Hepatic metastases is associated with poor efficacy of Erlotinib as 2nd/3rd line therapy in patients with lung Adenocarcinoma. Med Sci Monitor 2016;22:276-83. 